nitrous oxide. Davy, freeing himself from Beddoes, who was his patron, carved out a metropolitan career as lecturer and scientific genius, articulating a conservative version of chemistry serving a stable and stratified society. The Priestleian invocation of public participation in scientific demonstration was replaced by awe for the specialist surrounded by his instruments. Here Davy adopted the rhetorical and technical practices of Lavoisier, so castigated by Priestley.

Golinski sees the chemistry of the period intimately bound up with the fortunes of enlightened values and forms of civic life, not as conditioning factors but as intrinsic to the development of chemistry as a science. The concerns of his study are directly congruent with those of social and cultural historians to chart the role of intellectual life in public culture. As Knight observes, for all the lip service paid to the age of science', historians have remained largely impervious to the historical impact of science. It is to be hoped that Golinski's study will help to establish the central importance of science in the mainstream of historical study.

Peter Harman is in the Department of History, University of Lancaster, Lancaster LA1 4YG, UK.

- The newly launched Fontana History of Science Series, edited by Roy Porter, aims to provide a comprehensive synthesis for historians, scientists and nonspecialists. The first two titles on chemistry (by W. H. Brock; received too late for inclusion here) and the environmental sciences (by P. J.

Bowler) will be reviewed in a future issue of Nature.

\title{
The promiscuous primate
}

\section{Adrienne Zihlman}

The Last Ape: Pygmy Chimpanzee Behavior and Ecology. By Takayoshi Kano. Stanford University Press: 1992. Pp. 248. $\$ 45$.

PYGMY chimpanzees (Pan paniscus) differ from the better known species (Pan troglodytes) in walking more frequently on two feet, having sex more often and being less aggressive and more friendly. Except for the pelvis, the $P$. paniscus skeleton shows a striking resemblance to fossils of the earliest hominid, Australopithecus. So $P$. paniscus provides an alternative and in some ways more congenial model than $P$. troglodytes for the common ancestor of apes and humans, a model much debated during the past decade.

Contributing to this debate, Takayoshi Kano's delightful book summarizes his more than 10 years of field research on pygmy chimpanzees. Although published in 1985 in Japanese "for lay people interested in animals", it remains a useful overview of chimpanzee ecology and behaviour. Evelyn Ono Vineberg has done primatology a service with her clear translation of this succinct and informative volume.

When Kano began his initial survey of the forests of the Zaïre River Basin in 1973 , nothing was known about the freeranging population of pygmy chimpanzees. In the best tradition of Japanese long-term primate studies, Kano and colleagues have since been carefully accumulating observations of this elusive species. They have learned that pygmy chimpanzees are unusual among primates in that males, not females, maintain lifelong closeness to their mothers, and Kano believes that the lack of both but eventually stay in one group and, after giving birth, become stable members. "This reminds me of a new Japanese bride", Kano remarks, "who bravely enters the groom's large household. If she marries the oldest son, she may also have to live with her husband's parents and the unmarried brothers and sisters of her husband. Because she is picked on by in-laws, and her own family is distant, the new bride is often under great stress." Nevertheless, $P$. paniscus society is much less hierarchical than that of $P$. troglodytes and males do not show the same dominance over females.

Although it has become popular to use the term 'bonobo' for $P$. paniscus, Kano sticks to the original name 'pygmy chimpanzee', which emphasizes the demonstrated close genetic relationship between the two species. 'Bonobo' was introduced into the literature in 1954 by E. Tratz and M. Heck as a native name for the animal, but during his work throughout the region, Kano never heard this word spoken by local people. Its use in the current literature has taken on some political overtones, sometimes implying that the animal is not a true chimpanzee or perhaps not a chimpanzee at all.

Japanese primatologists have traditionally provisioned their study groups, including those of pygmy chimpanzees, a controversial practice said to alter the nutritional state, social interactions and organization of group members. This criticism has also at times served to imply that a few hours of observation of a few animals by researchers who do not provision is somehow more authentic than the years of patient and persistent work done by Japanese primatologists. Kano estimates that pygmy chimpanzees depend on provisioning for about 1.5 months every year. But without provisioning, there would be few observa\& tions to report, owing to the density of the forest habitat. Like so much in life and research, there is a trade-off.

An invaluable feature of the book is the detailed comparison of $P$. paniscus behaviour with that of $P$. troglodytes. What emerges is a comprehensive picture of the genus Pan. The book therefore provides an excellent foundation for integrating from continuing studies new data presented in the primary literature.

It is remarkable that so much information could be so pleasantly and efficiently enclosed in a mere 248 pages, including 12 figures, 8 maps, 26 tables and 78 photographs - all tied together with a relaxed and lucid prose style. The book, like its subject, is a model that anthropologists will study with great interest. $\square$

Adrienne Zihlman is in the Department of Anthropology, University of California, Santa Cruz, California 95064, USA. 